\title{
O ART.376 CPC E A PROVA DO DIREITO ESTRANGEIRO: AS IDAS E VINDAS DE UM EQUÍVOCO NA LEGISLAÇÃO PROCESSUAL BRASILEIRA
}

PROOF OF FOREIGN LAW AND THE CIV.PROC. COD. \$307 (2015): THE COMINGS AND GOINGS OF A MISCONCEPTION IN THE BRAZILIAN PROCEDURAL LAW

Paul Hugo Weberbauer Doutor em Direito pela Universidade Federal de Pernambuco. Natural de Bad Oeynhausen - NRWAlemanha. Professor Adjunto da Faculdade de Direito do Recife/UFPE - Direito Internacional Privado. Recife/PE. Email: paul.weberbauer@ufpe.br

Ariadnée Abreu de França Mestranda em Direito Internacional pela Universidade Federal de Pernambuco-UFPE. Pós graduada em Direito Digital e Compliance pela Faculdade de Direito Damásio de Jesus. Advogada especialista em Direito Digital e Compliance. João Pessoa/PB. E-mail: adv.ariadneeabreu@hotmail.com

RESUMO: O presente artigo procura desenvolver uma análise descritiva e crítica sobre a situação do instituto da prova de direito estrangeiro e seu tratamento no art.376 CPC, procurando comprovar a hipótese de que a manutenção da redação do revogado art.337 CPC/73 causa uma estagnação na matéria não compatível com a dinâmica. Com este escopo, o estudo se divide na compreensão da natureza processual do Direito estrangeiro e o significado do termo "prova" quando associado àquele; e, posteriormente, analisa-se 
como essa natureza influenciou na fórmula legislativa que hoje ainda se manifesta no art.376 CPC, em especial, nas na estagnação da legislação brasileira sobre a matéria.

PALAVRAS-ChAVE: Prova do Direito Estrangeiro, Prova processual, art. 376 CPC, Direito Internacional Privado, Processo Civil

ABSTRACT: This article seeks to develop a descriptive and critical analysis of the situation of the institute of proof of foreign law and its treatment in Civ. Proc. Code $\$ 376$ (2015), seeking to prove the hypothesis that the maintenance of the wording of revoked Civ. Proc. Code $\$ 337$ CPC (1973) creates a stagnation detrimental to the dynamics of legal relations of the 21 st Century. With this scope, the study is divided into the understanding of the procedural nature of foreign law and the meaning of the term "proof" when associated with it; and, later, it analyzes how this nature influenced the legislative formula that is still used today, which the $\$ 376 \mathrm{CPC}$ is its latest manifestation, trying to demonstrate how this is a mistake in dealing with foreign law proof.

KEY WORDS: Proof of Foreign Law, Evidence, §376 CPC, Conflict of Laws (Private International Law), Civil Procedure.

\section{INTRODUÇÃO}

Não é temerário afirmar que um dos campos mais complexos de estudos do Direito Internacional Privado é a questão da aplicação do Direito estrangeiro, ou melhor, como aplicar o direito estrangeiro incidente por força de norma colisional. É o entrelaçamento entre Direito Internacional Privado e Direito processual, dando ao surgimento ao instituto conhecido vulgarmente como Prova do Direito Estrangeiro.

É dentro deste campo que o presente estudo procura demonstrar que boa parcela de sua complexidade decorre da mau trato legislativo sobre a questão, adotando o que se pode denominar de "formula legislativa" arcaica e dotada de equívocos, qual acabou sendo mantida no art.376 do CPC, quando este simplesmente "copiou e colou" o art. 337 do CPC anterior. 
$\mathrm{Na}$ tentativa demonstrar esses equívocos, o estudo inicia-se como a delimitação da natureza do Direito estrangeiro, procurando demonstrar através de um estudo comparativo baseadas na doutrina do common Law e do Direito germânico, de que se trata de um pseudo debate cuja perpetuação acadêmica mais atrapalha do que auxilia na inserção do Direito estrangeiro na ordem nacional.

No segundo momento procede-se para a delimitação do significado técnico da palavra "prova" na expressão prova do direito estrangeiro, demonstrando que não se a utiliza na acepção processual (instrumento de veracidade de fatos), mas sim em uma acepção mais ampla, sinônimo de informação, de informar sobre algo.

No terceiro momento, estabelece-se o momento de origem da formula legislativa processual para a regulamentação do assunto, analisando-se as partes introdutórias criadas no século XIX para o que resultará na atual Lei de Introdução das Normas do Direito brasileiro, bem como a legislação processual da época, com destaque a consolidação da leis processuais, dos Códigos processuais estaduais e o CPC de 1939.

Para, no último momento, demonstrar como a repetição dessa fórmula criada nos primórdios da codificação processual civil e direito civil ignorou a evolução da matéria no plano do Direito Internacional Privado durante o século XX e XXI e manteve um sistema arcaico e desnecessariamente complexo sobre a aplicação do Direito estrangeiro pelo judiciário brasileiro em pleno século XXI.

Sob aspecto metodológico, o estudo utiliza da dedução como vetor principal, aportada pela investigação histórico-comparativa, adotando como fontes a legislação e as principais obras doutrinarias sobre o tema.

\section{O PSEUDODEBATE SOBRE FATO E DIREITO NA NATUREZA DO DIREITO ESTRANGEIRO}

Desde a ascensão das codificações a partir no final do século XVIII, um dos temas mais complexo do Direito Internacional Privado foi a natureza do direito estrangeiro a ser aplicável, quando o juiz enfrentava a questão de aplicar o Direito estrangeiro, este é considerado como fato ou como Direito? 
Não é temerário afirmar que até a primeira metade do século $\mathrm{XX}$, o entendimento dominante nessa questão era crença de que o Direito estrangeiro é um fato, não podendo ser aplicado sem a invocação e prova pelas partes processuais. Esse entendimento surgiu quando a jurisprudência francesa se deparou com a lacuna no Direito francês da época sobre o assunto e determinou o favorecimento do direito nacional sobre o direito estrangeiro ${ }^{1}$.

Os principais motivos da dominância inicial de compreender o direito estrangeiro como fato foi a poderosa influência do common Law e da constatação de que, no século XIX, as questões envolvendo aplicação do direito estrangeiro eram diminutas e o nacionalismo dominante acabava por gerar o favorecimento da aplicação do Direito nacional $^{2}$.

De forma bem simples, a compreensão do Direito estrangeiro no common Law concebeu uma formulação ortodoxa, pois no primeiro momento o equipara ao Direito nacional mas, ao mesmo tempo, diferente, pois sua apreciação judicial seria como questão de fato, logo era um Direito equiparado que necessitava de prova por ser uma questão de fato para fins de aplicação judiciária ${ }^{3}$.

Essa concepção ortodoxa do Direito estrangeiro tem sua explicação no sistema de fixação de competências entre trials by jury e bench trials, situação bem evidente no Direito estadunidense, no qual, por força da Amendment VII estabeleceu que todas questões de fato com valor superior a vinte dólares estadunidenses seriam competência do júri, ou

\footnotetext{
1 "Quanto à França, o código civil é omisso, mas a jurisprudência estabeleceu que o direito extrangeiro é um facto, cuja prova incumbe às partes, e, no caso, de abstenção destas, entende-se que a lei extrangeira é idêntica á francesa. Prova-se a lei extranjeira por todos os modos acceitos no direito commum, salvo o juramento decisório; e o juiz aprecia soberanamente o valor das offerecidas. Esta é a orientação dominante nas legislações" (BEVILAQUA, Clovis. Princípios elementares de direito internacional privado. Campinas: RED Livros, 2002, p.69).

2 "À medida que o DIP progrediu, que veio a ser objeto de textos expressos internos ou internacionais, ordenando a aplicação da lei estrangeira, a condição desta evoluiu, ultrapassada a fase primitiva, do territorialismo agressivo das soberanias, da ausência de normas de DIP que o juiz e a doutrina criavam "comitas gentium", onde a lei estrangeira, de regra desconhecida, era aplicada apenas por tolerância, e, assim, um puro fato a ser invocado, alegado e provado no processo pelos interessados".(VALLADÃO, HAROLDO. Direito internacional privado: em base histórica e comparativa, positiva e doutrinaria, especialmente dos Estados americanos. Introdução e Parte Geral. Rio de Janeiro: Livraria Freitas Bastos S.A., 1968, p.470).

3 "Foreign law is presumed to be the same as English, of course excluding those parts of the latter which only exist as special institutions with special machinery, as bankruptcy; the existence and operation of such institutions in any foreign country and in other respects the difference between foreign and English law, must be averred and proved bz any part, plaintiff or defendant, who relies on it". WESTLAKE, John. A treatise on private international law with principal reference to its practice in England. London: William Maxwell \& Son, 1880, p.323).
} 
melhor, as partes tem o direito de serem julgadas por um júri sobre matéria envolvendo fatos, direito este hoje regulado no $\$ 38$ US Federal Rules of civil Procedure ${ }^{4}$.

Logo, a natureza jurídica do Direito estrangeiro no common Law tem em seu cerne uma questão instrumental de fixação de competência e gerou a indagação de o Direito estrangeiro ser um fato para o Júri decidir ou seria um fato para a Corte decidir no momento anterior a instrução do Júri? A resposta inicial para essa indagação foi conceber que objeto do Direito Estrangeiro a ser provado seria delimitado pelas Cortes, enquanto que os meios de sua prova restariam ao cargo do Júri ${ }^{5}$.

Essa sistemática demonstrou-se demasiadamente problemática para os procedimentos que envolvessem a aplicação do Direito estrangeiro, pois os meios de prova sempre resultavam no incidente de testemunhos de peritos para esclarecer a questão a ser provada, levando uma lentidão e um aumento considerável dos custos do processo; como também restringiu a própria revisão de uma aplicação equivocada do Direito estrangeiro provado, pois as Cortes de apelação não podiam revisar o conteúdo de matérias julgadas pelo júri. Destarte, tornavam-se possíveis decisões imprecisas e incorretas, além da

\footnotetext{
4 "Rule 38. Right to a Jury Trial; Demand
}

(a) Right Preserved. The right of trial by jury as declared by the Seventh Amendment to the Constitution — or as provided by a federal statute-is preserved to the parties inviolate.

(b) Demand. On any issue triable of right by a jury, a party may demand a jury trial by:

(1) serving the other parties with a written demand - which may be included in a pleading - no later than 14 days after the last pleading directed to the issue is served; and

(2) filing the demand in accordance with Rule 5(d).

(c) Specifying Issues. In its demand, a party may specify the issues that it wishes to have tried by a jury; otherwise, it is considered to have demanded a jury trial on all the issues so triable. If the party has demanded a jury trial on only some issues, any other party may — within 14 days after being served with the demand or within a shorter time ordered by the court — serve a demand for a jury trial on any other or all factual issues triable by jury.

(d) Waiver; Withdrawal. A party waives a jury trial unless its demand is properly served and filed. A proper demand may be withdrawn only if the parties consent.

(e) Admiralty and Maritime Claims. These rules do not create a right to a jury trial on issues in a claim that is an admiralty or maritime claim under Rule 9(h)." (UNITED STATES OF AMERICA. Federal Rules of Civil Procedure: rule 44.1 Determining Foreign Law. In: Legal Information Institute. Disponível online em https://www.law.cornell.edu/rules/frcp/rule 38 acessado em 7 de junho de 2017).

5 "But, it may be asked, whether they are to be proved as facts to the jury if the case is a trial at the common law, or as facts the Court. It would seem as facts to the latter; for all matters of law are properly referable to the court, and the object of the proof of foreign laws is to enable the Court to instruct the jury, what, in point of law is the result of the foreign law to be applied to the matters in controversy before them". (STORY, Joseph. Commentaries on the conflict of laws, foreign and domestic, in regard to contracts, rights, and Remedies, and especially in regard to marriages, divorces, wills, successions, and judgements. 2 nd ed. Union, New Jersey: The Lawbook Exchange ltda. 2005, p. 895) 
morosas, transformando o Direito estrangeiro como sinônimo de dor de cabeça para as partes litigantes ${ }^{6}$.

Ocorre que diferente da escassez de questões envolvendo a prova do direito estrangeira do séc. XIX, a segunda metade do século XX demostrou-se fecundo desse tipo de questões. Esse novo contexto pode ser bem compreendido com o caso Siegelman $v$. Cunard White Star de 1951, qual figura hoje como um dos principais leading case na mudança de paradigma sobre a natureza do Direito estrangeiro no common Laws.

O caso envolvia um pleito de indenização por ferimentos decorrentes a bordo do S.S. Queen Elizabeth, e foi iniciada na Corte do Estado de Nova Iorque, porém redistribuída para a Corte Distrital local, com sugestão de arquivamento sob fundamento de que por força contratual, qualquer pedido de indenização deveria ter sido exercido dentro de 01 (um) ano contado a partir da data do ferimento, assim sendo, o fermento ocorrera em 1949, o pleito indenizatório deveria ter sido proposto em 1950, porém o pleito foi protocolado em 1951, quando o prazo decadencial havia se expirado ${ }^{7}$.

Delimitando a questão ao direito estrangeiro, a Corte Distrital agiu de forma contraditória, pois ignorou a sugestão da Corte estadual e entendeu que o prazo de indenização somente poderia ter sido alterado para um ano se o aditamento contratual feito tivesse sido assinado pelo agente-chefe do porto de embarque, logo, decidiu a questão

\footnotetext{
6 "When U.S. courts treated foreign law as a question of fact prior to the adoption of Rule 44.1, the júri needed to decide foreign law based on competing proofs presented by the parties at trial. This was done pursuant to the rules of evidence via the time-consuming process of soliciting expert witness testimony in open court. Also, because foreign law was considered as a question of fact, it could only be set aside by an appellate court if shown to be clearly erroneous. This cumbersome system was arduous for the parties, and often resulted in imprecise rulings, that were essentially immunized from independent review by the appellate courts". (WILSON, Mathew J. Demystifying the determination of foreign law in U.S. courts: opening the door to a greater global understanding. Akron Law Publications. Paper 227 disponível online em http://ideaexchange.uakron.edu/ua_law_publications/227 acessado em 7 de junho de 2018.)

7 "The complaint in that action alleges that on September 24, 1949, while plaintiff's wife was a passenger on the S.S. Queen Elizabeth, she suffered an injury when both she and the dining room chair, in which she was seated, were overthrown by the action of the sea. The answer, in addition to a general denial, alleges that the passenger had assumed the risk of the voyage, and also, that the passage was governed by the terms and conditions of the ticket which provided that there could be no recovery from damage due to dangers of the sea or acts of God. It was also alleged as a defense that the ticket contract required a suit to be commenced within one year from the day of injury, and that since the action was brought on December 14, 1951, the contract had not been complied with and that recovery was barred. The suit, which had been commenced in the New York State court, was re- moved to the federal courts on the grounds of diversity. A motion was made in the District Court for a dismissal of the complaint, on the ground that the action was barred by the period of limitations specified in the contract". (BUSCH, Benjamin. When Law is Fact. Fordham Law Review. Vol. 24. Issue 646, 1955, p.647 disponível online em http://ir.lawnet.fordham.edu/flr/vol24/iss4/8 acessado em 7 de junho de 2018).
} 
utilizando da interpretação do contrato e seu contexto, mas ignorou que o porto de embarque estava localizado na Inglaterra, não nos EUA, e por força do local do ato, o contrato estaria submetido ao Direito inglês, o qual nenhuma das partes havia invocado ${ }^{8}$.

Diante dessa situação confusa criada pela Corte Distrital, o caso foi levado a Corte de Apelações dos Estados Unidos, a qual, por decisão majoritária, determinou que o contrato e a indenização estavam sujeitos ao Direito inglês e que "it was within its competence to apply English Law, because pleading foreign law is unnecessary and because judicial notice could be taken of foreign law whether or not pleaded or proved 9 ".

A partir dessa decisão da Corte de Apelações, surgiu o entendimento de que Direito estrangeiro é matéria de direito (question of law - matter of law) e que tanto a delimitação quando aplicação caberia as Cortes decidirem, não ao júri. Bem como esse procedimento poderia recorrer as provas fornecidas pelas partes, como também por qualquer outra fonte de informação disponível. Entendimento que se solidificou com a alteração em 1966 da rule 44.1 do Federal Rules of civil Procedure, consagrando, ao menos a nível de direito federal, que Direito estrangeiro é uma questão de direito, mesmo exigindo invocação pela parte $^{10}$.

\footnotetext{
8 "No reference was made to English law by either of the parties upon the hearing of the motion to dismiss. Upon that state of the record, there would have been authority for a determination by the District Court that the law of this jurisdiction is the only law before the court in the absence of proof of the law of the foreign jurisdiction; or stated in another manner, the failure of the parties to prove foreign law raised the presumption that they acquiesced in the application of the law of the forum. The District Court relied upon neither of these presumptions and based its opinion upon the language of the contract which provided for the one year limitation for suits and which made invalid any changes in the contract unless signed by the chief agent at the port of embarkation, and which required all questions arising on the contract to be decided according to English law. The only question which the court considered decisive was whether a claim agent could, under British law, waive the one year contractual limitation. After pointing out that under New York law, the modification of a contractual limitation must be in writing and signed by the chief agent at the port of embarkation, the opinion states: "There has been no allegation or proof that the law of England is different from that of New York,"" and English precedent is cited7 to show that the law of England is allegedly in accord with the law of New York, as stated" (BUSCH, Benjamin. When Law is Fact. Fordham Law Review. Vol. 24. Issue 646, 1955, p.648 disponível online em http://ir.lawnet.fordham.edu/flr/vol24/iss4/8 acessado em 7 de junho de 2018).

${ }^{9}$ BUSCH, Benjamin. When Law is Fact. Fordham Law Review. Vol. 24. Issue 646, 1955, p.649 disponível online em http://ir.lawnet.fordham.edu/flr/vol24/iss $4 / 8$ acessado em 7 de junho de 2018

10 "Rule 44.1. Determining Foreign Law. A party who intends to raise an issue about a foreign country's law must give notice by a pleading or other writing. In determining foreign law, the court may consider any relevant material or source, including testimony, whether or not submitted by a party or admissible under the Federal Rules of Evidence. The court's determination must be treated as a ruling on a question of law" ((UNITED STATES OF AMERICA. Federal Rules of Civil Procedure: rule 44.1 Determining Foreign Law. In: Legal Information Institute. Disponível online em https://www.law.cornell.edu/rules/frcp/rule_44.1 acessado em 7 de junho de 2017).
} 
Rio de Janeiro. Ano 13. Volume 20. Número 3. Setembro a Dezembro de 2019

Periódico Quadrimestral da Pós-Graduação Stricto Sensu em Direito Processual da UERJ

Patrono: José Carlos Barbosa Moreira (in mem.). ISSN 1982-7636. pp. 386-408 www.redp.uerj.br

Em suma, a redução do Direito estrangeiro como um fato, foi uma característica de um período em que Direito Internacional como um todo (tanto Público, como Privado) eram considerados moral positiva ou, quando muito, ramos imperfeitos ou incomuns da Ciência Jurídica, cuja aplicação era mais uma faculdade das jurisdições nacionais do que um dever, um ofício do Judiciário nacional. A territorialidade da jurisdição havia atingido seu ápice no Estado nacional do século XIX.

Por sua vez, na Europa continental, a gradual quebra da concepção do Direito estrangeiro como fato pode ser compreendida através de uma análise da promulgação do Zivilprozessordnung (ZPO) - as ordenanças processuais civis alemãs. - em 1877, quando em seu $§ 265$ determinou a aplicação do Direito estrangeiro só necessitava de prova na medida em que fosse desconhecido pelo juízo ${ }^{11}$.

A doutrina germânica acabou constatando que ao afirmar que o Direito estrangeiro era um fato, estava-se negando a própria obrigatoriedade das normas de Direito Internacional Privado, mais especificamente, a obrigatoriedade de aplicação da Einführungsgesetz zum Bürgerlichen Gesetzbuch de 1896. Some-se que qualquer permissão para tal compreensão nega a própria extraterritorialidade das normas ${ }^{12}$.

Não sem motivo, o Direito estrangeiro é matéria de direito e, portanto, a ser aplicada ex officio pelo juiz, cabendo somente a sua informação quando desconhecida ou de difícil compreensão ser produzida pelo próprio juiz e com auxílio das partes, conforme

\footnotetext{
11 “§. 265.Das in einem anderen Staate geltende Recht, die Gewohnheitsrechte und Statuten bedürfen des Beweises nur insofern, als sie dem Gericht unbekannt sind. Bei Ermittlung dieser Rechtsnormen ist das Gericht auf die von den Parteien beigebrachten Nachweise nicht beschränkt; es ist befugt, auch andere Erkenntnißquellen zu benutzen und zum Zwecke einer solchen Benutzung das Erforderliche anzuordnen" (DEUTSCHER REICHSANZEIGEN: Amtliches Mitteilungsblatt des Deutschen Reiches. Civilprozeßordnung Buch 2, disponível online em https://deutscherreichsanzeiger.de/Gesetze/blog/1877/02/19/cpo-buch-2/ acessado em 01 de junho de 2018).

12 "Die Nöte der Praxis resultieren bei genauer Betrachtung gar nicht aus der Anwendung des IPR, sondern aus der Anwendung eines vom IPR gegebenenfalls berufenen Auslandsrechts. Insoweit türmen sich vor dem normalen Rechtsanwender Informationsprobleme auf, nicht selten verschärft durch Sprachprobleme. Vor diesen Problemen weichen Anwälte und Gerichte gerne aus. Das probateste Mittel dazu ist eben, den Auslandsbezug des Sachverhalts rechtlich nicht aufzugreifen und einfach deutsches Sachgerecht anzuwenden, als handelte es sich um einen reinen Inlandsfall. Das IPR wir so de facto zum fakultativen Kollisionsrecht: Es wird erst angewendet, wenn sich einer der Beteiligten auf es beruft." Von BAR, Christian; MANKOWSKI, Peter. Internationales Privatrecht.Band I - Allgemeine Lehren. München: Verlag C.H. Beck, 2003, vol. 1, p.393).
} 
o §293 da Zivilprozessordnung (ZPO) (ordenação processual civil) alemã ${ }^{13}$, o qual, por sua vez, tem sua redação praticamente idêntica ao §265 da ordenação anterior.

$\mathrm{Na}$ esteira dessa constatação, a doutrina germânica estabeleceu que o Direito estrangeiro é Direito e, com isso, ratificou que o Direito Internacional Privado consiste em um ramo jurídico como qualquer outro.

Verifica-se, portanto, uma aproximação entre a doutrina anglo-saxônica e a doutrina germânica em tratar o direito estrangeiro como Direito, evidenciando que não há mais espaço para doutrinas baseadas na concepção de Fato, pelas dificuldades práticas e teóricas que essa concepção cria para a aplicação do Direito.

\section{O SIGNIFICADO DE "PROVA" NA PROVA DO DIREITO ESTRANGEIRO}

O instituto da prova no Direito processual tem uma intrínseca relação com o convencimento do juiz sobre a veracidade dos fatos fundamentos do pedido, ou seja, prova processual é um meio de convencimento sobre fatos, uma parâmetro de veracidade, ou nas palavras de Chiovenda: "provar significa formar a convicção do juiz sobre a existência ou não de fatos relevantes no processo ${ }^{14}$ ".

$\mathrm{Na}$ esteira desse campo conceitual, ensina Carnelutti que o conceito jurídico de prova significa "a demonstração da verdade legal de um fato ${ }^{15}$ ", mais precisamente, que a prova é "em seu sentido jurídico a demonstração da verdade formal ou judicial, ou dizer, entretanto, que é a determinação formal dos fatos discutidos ${ }^{16}$ ".

A lição desses dois grandes processualistas possibilita distinguir o conceito de prova em dois aspectos principais: um centralizado no instrumento de convencimento do juiz da veracidade sobre algo, e outro centralizado na ideia de informação, revelação de algo até então desconhecido.

${ }^{13}$ BAUMBACH, Adolf; LAUTERBACH, Wolfgang; HARTMANN, Peter. Zivilprozessordnung. 62 ed. München: Verlag C. H. Beck, 2004, p.1153-1154.

${ }^{14}$ CHIOVENDA, Giuseppe. Instituições de direito processual civil. Tradutor: Paolo Capitanio. $3^{\mathrm{a}}$ ed. Campinas: Bookseller, vol. III, 2002, p.109

${ }^{15}$ CARNELUTTI, Francesco. A prova civil. Tradução: Lisa Pary Scarpa. Campinas: Bookseller, 2002, p.72.

${ }^{16}$ CARNELUTTI, Francesco. A prova civil. Tradução: Lisa Pary Scarpa. Campinas: Bookseller, 2002, p.73. 
Desta divisão analítica pode-se estabelecer que a prova processual é um instrumento de convencimento do juiz sobre a veracidade do Fato alegado; enquanto que a prova do Direito estrangeiro é baseada na produção da informação sobre o mesmo.

Essa distinção fica mais clara quando se procede a analisar o art. $3^{\circ}$ da Convenção de 1979, qual admite a informação do direito estrangeiro por qualquer meio, desde que seja idôneo tanto na lei do Estado requerente como na lei do Estado requerido ${ }^{17}$.

Ao se constatar essa distinção analítica, torna-se possível concluir que a prova do direito estrangeiro é denominada de forma equivocada, pois se trata de informação sobre algo desconhecido, não como meio de medir a veracidade de algo. Portanto, a prova do Direito Estrangeiro é informação, que é prestada por qualquer meio idôneo de prova se desconhecido o direito alienígena.

Logo, a denominação mais correta deste instituto é o de informação sobre o Direito estrangeiro e sua classificação temática no processo civil é a de matéria de cooperação internacional, não de prova.

A utilização dessa denominação também tem como benéfico de extinguir eventual confusão entre os institutos da informação sobre o Direito estrangeiro da prova estrangeira, esta última é o meio de comprovação de um fato alegado em juízo que é realizada e obtida fora da jurisdição nacional do foro da lide.

\section{A ORIGEM DA REGULAMENTAÇÃO LEGISLATIVA SOBRE A INFORMAÇÃO DO DIREITO ESTRANGEIRO}

\subsection{A QUESTÃO NO DIREITO CIVIL E DIREITO INTERNACIONAL PRIVADO}

Apesar da primeira notícia que se encontrou sobre a questão da prova do Direito estrangeiro remete as Ordenações filipinas, quando no livro III, título LIII 8 e 9 quando

\footnotetext{
17 “A cooperação internacional na matéria de que trata esta Convenção será prestada por qualquer dos meios de prova idôneos previstos tanto na lei do Estado requerente como na do Estado requerido" (BRASIL. Decreto $\mathbf{n}^{\circ} 1.925$, de 10 de junho de 1996. Promulga a Convenção Interamericana sobre prova de informação acerca do Direito Estrangeiro, concluída em Montevidéu, Uruguai, em 8 de maio de 1979. Disponível online em http://www.planalto.gov.br/ccivil_03/decreto/1996/D1925.htm acessado em 08 de junho de 2018.
} 
regulando "em que modo se farão os artigos, para as partes serem obrigadas depôr a eles" dispõe que que havendo questões envolvendo "articulação de Direito de outro Reino" se for de"lugar certo, pode-se provar; e tudo o que se póde provar, se pode per Direito $\operatorname{articular"~}^{\prime 18}$. Bem aponta Pontes de Miranda que essa regulamentação nas Ordenações em nada se relaciona a prova do Direito estrangeiro, ela regulamentava "a depoimentos e artigos"19

Destarte, não é temerário iniciar o estudo da questão do instituto da informação do Direito Estrangeiro no direito brasileiro a partir do esboço de Código Civil de Teixeira de Freitas, mais precisamente o art. $6^{\circ}$ daquela obra ${ }^{20}$.

A sistemática proposta sobre esse assunto de Teixeira de Freitas pode-ser compreendida através de duas constatações: a influência do nacionalismo e confusão entre tratado e lei estrangeira.

A influência do nacionalismo se demonstra quando se verifica nos comentários de sua obra, a convicção de que somente poderia ser considerado direito aquilo que fosse emanado dentro do Estado nacional, ou como o próprio Teixeira de Freitas coloca: "lei nacional é direito, que simplesmente se allega sem depender de prova. Uma lei estrangeira é um facto, que deve ser provado ${ }^{21}$ ".

A partir dessa associação, dominante no século XIX, a opção de reduzir o Direito estrangeiro a fato ocorre pela própria concepção do juiz no processo, devido ao fato de estar implícito na função de juiz o mesmo conhecer o direito, não se poderia exigir que estes "conhecessem todas as leis de todo o mundo ${ }^{22}$ ".

Também influenciaram a compreensão do Direito estrangeiro no esboço de Código Civil a confusão entre lei estrangeira e tratado, demonstrada na redação do art. $7^{\circ}$ no qual se

\footnotetext{
${ }^{18}$ ALMEIDA, Candido M. de. Código philippino ou ordenações e leis do reino de Portugal recompiladas por mandado d'el-rey D. Philippe I. 14 ed. Rio de Janeiro: Typhographia do Instituto Philomathico, 1870, t.3, p. 638-639.

19 PONTES DE MIRANDA, Francisco C. Tratado de Direito internacional privado. Tomo I Fundamentos e parte geral. Rio de Janeiro: José Olympio Editora, 1935, p.365.

20 "A aplicação de leis estrangeiras nos caos, em que êste Código a autorisa, nunca terá lugar senão a requerimento das partes interessadas; incumbindo á estas, como prova de um facto allegado, a da existência de tais leis" (FREITAS, Augusto Teixeira de. Código Civil: esboço por A. Teixeira de Freitas. Rio de Janeiro: Ministério da justiça e negócios interiores, 1952, p.6.)

${ }^{21}$ FREITAS, Augusto Teixeira de. Código Civil: esboço por A. Teixeira de Freitas. Rio de Janeiro: Ministério da justiça e negócios interiores, 1952, p.6.

${ }^{22}$ FREITAS, Augusto Teixeira de. Código Civil: esboço por A. Teixeira de Freitas. Rio de Janeiro: Ministério da justiça e negócios interiores, 1952, p.6.
} 
tornavam direito as leis estrangeiras que fossem tornadas obrigatórias no Império brasileiro, seja por lei especial ou por convenção diplomática ${ }^{23}$.

Não sem razão, a leitura conjunta dos dispositivos $6^{\circ}$ e $7^{\circ}$ acabam em demonstrar uma evidente contradição, pois a lei estrangeira incorporada, não é mais lei estrangeira; e, se as próprias regras do Esboço levam a aplicação de direito estrangeiro (ex. arts. 25 e 26), por que esse direito estrangeiro incidente deveria ser provado, se sua aplicação decorreu pela próprio esboço?

Em sua essência, a proposta de Teixeira de Freitas era uma mistura, ou melhor, um pensamento sincretista, pois adotava no art. $6^{\circ}$ a postura francesa de conceber direito estrangeiro como fato - pensamento nascido no início do século XIX- mas, ao mesmo tempo, o art. $7^{\circ}$ adotava uma linha de pensamento que ficou conhecida como Teoria da recepção, cuja premissa é, justamente, de que "uma regra qualquer de direito estrangeiro só teria valor se fosse incorporada ao direito local - ou seja, recebida por este" 24 .

Interessante é que apesar de constar na primeira tentativa de codificação civil brasileira, o instituto da informação do Direito estrangeiro acabou não sendo inserido na Codificação de 1916.

Dos 21 artigos que compuseram a Introdução do Código Civil de 1916, somente o art.12 ocupou-se em regular questões envolvendo prova, mais precisamente, regulamentava que o direito aplicável aos meios de prova serrano regulados pela lei do local onde se faz a prova - locus regia actum ${ }^{25}$.

Em análise dos documentos referentes a elaboração da codificação de 1916, encontra-se que o motivo principal de não se regulamentar a prova das leis estrangeiras foi a constatação que o mesmo significaria um retrocesso, pois era princípio básico do Direito Internacional Privado de que a lei estrangeira era de aplicação obrigatória ${ }^{26}$.

${ }^{23}$ FREITAS, Augusto Teixeira de. Código Civil: esboço por A. Teixeira de Freitas. Rio de Janeiro: Ministério da justiça e negócios interiores, 1952, p.6.

${ }^{24}$ BAPTISTA, Luiz Olavo. Aplicação do direito estrangeiro pelo juiz brasileiro. In: BAPTISTA, Olavo \& MAZZUOLI, Valério de O (orgs.) Doutrinas essenciais de direito internacional: direito internacional privado: teoria e prática. São Paulo: Editora Revista dos Tribunais, 2012, p.1350.

25 "Art.12 Os meios de prova regular-se-ão conforme a lei do lugar, onde se passou o ato, ou fato, que se tem de provar". (BRASIL. Lei 3.071, de $\mathbf{1}^{\circ}$ de janeiro de 1916. Código Civil dos Estados Unidos do Brasil. Disponível online em http://www.planalto.gov.br/ccivil 03/Leis/L3071.htm acessado em 9 de junho de 2018.

26 "Restam as leis estrangeiras, cuja prova o artigo exige também. Quanto a estas leis, admitidos os princípios de direito internacional privado, já consignado no Título Preliminar do Projecto, as leis estrangeiras - diz o orador- que corresponderem ao nosso direito, devem ser leis observadas aqui tão inteiramente como o são as nossas próprias leis. Si, por exemplo, se disser que o brasileiro, nascido na Itália, tem a capacidade dada pela 
Desta breve análise histórica, pode-se constatar que a adoção da concepção de Direito estrangeiro como fato não nasceu da legislação do Direito civil, muito menos da legislação de Direito Internacional privado brasileiro, restando a indagação de onde veio a formulação da Lei de Introdução de 1942 e vigente ate hoje?

A resposta dessa questão está na legislação processual brasileira.

\subsection{O CRITÉRIO DA NECESSIDADE}

Sob aspecto da legislação processual, o ponto de partida é o Regulamento 737 de 25 de novembro de 1850, expandido para questões processuais civis pelo decreto $n^{\circ} .763$, de 19 de setembro de 1890. Mais precisamente, do que se denomina no presente estudo de critério da necessidade. Portanto a informação do Direito estrangeiro tem seu nascedouro legislativo na legislação comercial e sua expansão inicial sobre as regras processuais.

Importante ressalvar, que a doutrina nacional costuma adotar como nascedouro histórico da "prova do direito estrangeiro" no decreto 596 de 19 de julho de 1890, em especial o art. 34, qual atribuía às Juntas comerciais a tarefa ex oficio de solicitar "aos cônsules da República a remessa de leis e decisões dos tribunais estrangeiros, bem como informação exata dos usos comerciais alienígenas, a fim de tomarem assento declaratório da legislação, jurisprudência e usos atinentes a atos praticas no estrangeiro"27.

Discorda-se dessa posição e se considera a mesma equivocada, baseada na constatação de que o art.34 do decreto 596 regulamenta a organização das informações para funcionamento das próprias juntas comerciais, em nada se relacionado a questão de provas ou, até mesmo, informação processual sobre Direito Estrangeiro ${ }^{28}$.

lei brasileira, comprehende-se, pelo mesmo principio quero italiano, nascido no Brasil, tem a capacidade reconhecida pela lei italiana. A lei italiana, por esta forma, torna-se tão obrigatória aqui como a lei brasileira na Italia. Este é um princípio do direito internacional privado. Esta publicidade e obrigatoriedade da lei internacional é um consectario necessario do princípio da adopção do direito internacional privado. Dir-seha: Mas há dificuldade de prova. Esta dificuldade é nula. Si na Secretaria de Estrangeiros não existem hoje collecções destas leis, e porque se tem abandonado, se tem emprestado, se tem dado mesmo.Sabe que, de paizes estrangeiros, eram remetidas officialmente collecções de suas leis e sabe também que o Brasil, por sua vez, remettia a das suas". (ANDRADE FIGUEIRA, 14 $4^{\mathrm{a}}$ Reunião em 21 de outubro de 1901. In: BRASIL. Código Civil brasileiro: trabalhos relativos à sua elaboração. Rio de Janeiro: Imprensa Nacional, volume 3, p.291 - Disponível para descarregar em http://bd.camara.gov.br/bd/handle/bdcamara/14356 ).

${ }^{27}$ CASTRO, Amilcar de. Direito Internacional privado. Atualização: Osiris Rocha. 5 ed. Rio de Janeiro: Forense, 2004, p. 265.

28 “Art. 34. A mesma Junta, no uso da attribuição privativa que lhe confere o art. 13, n. 1, deverá solicitar dos consules da Republica a remessa das leis relativas aos actos de apresentação de letras de cambio, seu acceite, 
Rio de Janeiro. Ano 13. Volume 20. Número 3. Setembro a Dezembro de 2019

Periódico Quadrimestral da Pós-Graduação Stricto Sensu em Direito Processual da UERJ

Patrono: José Carlos Barbosa Moreira (in mem.). ISSN 1982-7636. pp. 386-408 www.redp.uerj.br

O que existe no decreto 596 é a atribuição ex officio das Juntas em se manterem informadas sobre as diferentes leis estrangeiras, bem como práticas comerciais estrangeiras para analisar atos de sua atribuição; e não um dever do juiz em prover informação da prova estrangeira ex officio. Tratava-se de um dever da junta quando lidando com comerciantes estrangeiros, dever este que foi transferido para a parte interessada no cadastro com a evolução do funcionamento das juntas comercias brasileiras no século $\mathrm{XX}^{29}$.

Acrescente-se que a regulamentação da prova do Direito estrangeiro já se encontrava presente no art.333 da Consolidação das Leis de Processo Civil de 1876, o qual adotava o critério da necessidade da prova ${ }^{30}$ e é anterior ao próprio decreto 596.

Superada essa questão inicial, o fundamento de defender que a fórmula mais próxima da que seria adotada pela legislação processual até na atual codificação processual civil de 2015, reside na redação do art.134 $\S 2^{\circ}$ do Regulamento 737, qual dispunha “ $§ 2^{\circ}$ Quando o contrato, ou facto que forem objecto da demanda, tiver acontecido no logar para o qual se pede carta de inquirição, e ao Juiz parecer essa prova necessaria".

Em síntese, a carta inquirição era um instrumento de coleta de prova testemunhal, podendo ser utilizada dentro ou fora da jurisdição do Império Brasileiro, utilizada nos casos em que as testemunhas não se encontrassem na jurisdição do Tribunal de Comércio, em analogia grosseira, é um dos antepassados jurídicos das cartas precatórias e rogatórias.

A importância desse dispositivo reside na liberdade do Tribunal de comércio em admitir a a produção da prova por carta de inquirição conforme a necessidade da causa, isto é, sua produção era facultativa, a critério da necessidade do juízo. Óbvio que não se trata da regulamentação de prova do direito estrangeira, mas é manifesta a presença da

endossos, pagamento, protestos e notificações nas praças dos seus districtos consulares, e das decisões dos tribunaes de ultima instancia que sobre taes actos se proferirem, bem como informação exacta dos usos commerciaes respectivos admittidos nas mesmas praças.

Obtidos os esclarecimentos necessarios, e ouvidas a Junta dos Corretores da Capital Federal e as Juntas Commerciaes dos Estados, tomará assento declaratorio da legislação e usos applicaveis aos referidos actos praticados no estrangeiro". (BRASIL. Decreto $\mathbf{n}^{\circ} \mathbf{5 9 6}$, de 19 de julho de 1890. Reorganiza as Juntas $e$ Inspectorias Commerciaes e dá-lhes novo regulamento. Disponível online em http://www2.camara.leg.br/legin/fed/decret/1824-1899/decreto-596-19-julho-1890-505086publicacaooriginal-1-pe.html acessado em 9 de junho de 2018.

${ }^{29}$ A regra atual é regida pelo art.11 da Instrução Normativa DREI n ${ }^{\circ}$ 7, de 05 de dezembro de 2013.

30 “Art. 333. O direito só se precisa provar, quando é singular, municipal, estrangeiro ou não escripto" (RIBAS, Antonio J. Consolidação das leis do processo civil. Com colloboração de seu filho Dr. Julio A. Ribas. Rio de Janeiro: Dias da Silva Junior Typographo-editor, 1879, v.01, p.248 disponível online para descarregar em http://www2.senado.leg.br/bdsf/item/id/220533 acessado em 9 de junho de 2018). 
formula da produção da prova conforme a necessidade do juiz sobre algo fora de seus jurisdição - o critério da necessidade.

A presente posição se solidifica ainda mais quando se analisa os códigos processuais estaduais que surgem com a Constituição de 1891 e na verificação da repetição do critério da necessidade ou, até mesmo, cópia da Consolidação de 1876, como pode se observar no art.183 do Código de Processo civil e commercial do Distrito Federal (Decreto $\mathrm{n}^{\circ}$ 16.752, de 31 de dezembro de 1924), qual estabelece que "Aquelle que alegar direito singular, estadual, estrangeiro, ou costumeiro deve provar sua vigência e teor, salvo se o juiz dele tiver conhecimento dispensar a prova ${ }^{31}$ ” e o art. 274 do Código de Processo Civil e commercial do Estado de São Paulo (lei ${ }^{\circ} 2.421$, de 14 de janeiro de 1930), qual dispõe: “O juiz poderá exigir a prova da lei municipal estrangeira ou de Estado diverso, invocada pela parte ${ }^{32}$,

\section{O CAMinho PARA A ESTAGNAÇÃo dA MATÉRIA ATÉ O ART.376 CPC/2015}

A era das codificações estaduais durou pouco. A descentralização das codificações processuais acabou gerando uma situação semi-anárquica no processo brasileiro, tanto que a regulamentação da prova do Direito estrangeiro nesse período, apesar de manter o critério da necessidade, podia variar conforme o Estado da federação: existindo àqueles que se filiaram a doutrina do common Law vigente da época, outras adotando a doutrina germânica, e, terceiros, adotando uma perigosa tendência eclética na matéria ${ }^{33}$

\footnotetext{
${ }^{31}$ DISTRITO FEDERAL. Decreto ${ }^{\circ}$ 16.752, de 31 de Dezembro de 1924. Põe em execução o Código do processo civil e commercial no Distrito Federal. Disponível online em http://www2.camara.leg.br/legin/fed/decret/1920-1929/decreto-16752-31-dezembro-1924-516249publicacaooriginal-139889-pe.html acessado em 09 de junho de 2018.

32 SÃO PAULO. Lei $\mathbf{n}^{\circ} \mathbf{2 . 4 2 1}$, de 14 de Janeiro de 1930. Código de Processo civil e commercial. Disponível online em https://www.al.sp.gov.br/repositorio/legislacao/lei/1930/lei-2421-14.01.1930.html acessado em 09 de junho de 2018

33 "No Brasil, em princípio, a lei estrangeira é lei, e não só facto, se bem que se trate como facto, por ser preciso prova dela. Aliás, cada um dos Códigos do Processo podia, a respeito, adotar o sistema angloamericano, ou o alemão, ou o intermédio, que é o mais vulgar, pôsto-que o mais perigoso pela elasticidade, pela vaguidade e pela imprecisão dos seus critérios" (PONTES DE MIRANDA, Francisco C. Tratado de Direito internacional privado. Tomo I - Fundamentos e parte geral. Rio de Janeiro: José Olympio Editora, 1935, p.365).
} 
Diante desse quadro, iniciou-se um poderoso movimento de centralização federal na matéria processual, iniciada com a reforma constitucional de 1926, materializada na Constituição de 1934 e manifesta no Código de Processo Civil de $1939^{34}$.

Aponta-se como "endereço doutrinário 35 " do Código de Processo Civil de 1939 (CPC/1939) as lições de Giuseppe Chovendo, Franz Klein e José Alberto dos Reis, mesclando influências italianas, austríacas e portuguesas na sua elaboração, por consequência ocorreu um rompimento com a vigente concepção privatista do processo, transformando o mesmo em um instituto de interesse público e um alargamento dos poderes do Juiz ${ }^{36}$.

Com este contexto doutrinário, não é de se espantar que o CPC/1939 não inovasse na regulamentação da informação do Direito estrangeiro, quando em seu art.212 determinou que "aquele que alegar direito estadual, municipal, costumeiro, singular ou estrangeiro, deverá provar-lhe o teor e a vigência, salvo si o juiz dispensar a prova".

Essa redação tem a forte influência da técnica legislativa que surgiu com a Consolidação de 1876 e que encontra ressonância nas lições de Chiovenda ${ }^{37}$, cuja doutrina seguia o entendimento de que o direito estrangeiro e direito consuetudinário eram exceções a obrigatoriedade do juiz em conhecer o direito, logo eram objeto de prova se o juiz não conhecesse desses direitos ${ }^{38}$.

A técnica legislativa dominante havia encontrado um arcabouço teórico sólido na matéria no CPC/1939, estava inaugurado a formula legislativa que será utilizada no o art.14 da Lei de Introdução às Normas do Direito brasileiro (LINDB) ("Não conhecendo a lei estrangeira, poderá o juiz exigir de quem a invoca prova do texto e da vigência"); no

\footnotetext{
${ }^{34}$ MACEDO, Elaine H. Jurisdição e processo. Crítica histórica e perspectivas para o terceiro milênio. Porto Alegre: Livraria do Advogado, 2005, p. 209.

${ }^{35}$ RAATZ, Igor \& SANTANNA, Gustavo da S. História do processo civil brasileiro: do código de 1939 ao código de 1973. In: Justiça e História. Porto Alegre: Tribunal de Justiça do Estado do Rio Grande do Sul, 2012, vol.9 $\mathrm{n}^{\circ} \quad 17$ e $18, \quad$ p. 7 disponível online em http://www.tjrs.jus.br/site/poder_judiciario/historia/memorial_do_poder_judiciario/memorial_judiciario_gau cho/revista_justica_e_historia/index.html acessado em 10 de junho de 2018.

${ }^{36}$ RAATZ, Igor \& SANTANNA, Gustavo da S. História do processo civil brasileiro: do código de 1939 ao código de 1973. In: Justiça e História. Porto Alegre: Tribunal de Justiça do Estado do Rio Grande do Sul, 2012, vol.9 $\mathrm{n}^{\circ} \quad 17 \quad$ e $18, \quad$ p. 12 disponível online em http://www.tjrs.jus.br/site/poder_judiciario/historia/memorial_do_poder_judiciario/memorial_judiciario_gau cho/revista_justica_e_historia/index.html acessado em 10 de junho de 2018.

${ }^{37}$ A influência de Chiovenda foi profunda no Código de 1939, devido ao fato de na exposição de motivos daquele diploma ocorrer reiteradas referências ao mesmo.

${ }^{38}$ CHIOVENDA, Giuseppe. Instituições de direito processual civil. Tradutor: Paolo Capitanio. $3^{a}$ ed. Campinas: Bookseller, vol. III, 2002, p.113.
} 
art. 337 do Código de Processo Civil de 1973 (“A parte, que alegar direito municipal, estadual, estrangeiro ou consuetudinário, provar-lhe-á o teor e a vigência, se assim o determinar o juiz"); e, finalmente, no art.376 do CPC/2015 (“A parte que alegar direito municipal, estadual, estrangeiro ou consuetudinário provar-lhe-á o teor e a vigência, se assim o juiz determinar").

Ocorre que essa fórmula legislativa inaugurou a manutenção de três equívocos: (i) o mal enquadramento do assunto no livro das Provas processuais; (ii) a problemática da invocação pelas partes, e (iii) regulamentação insuficiente.

Como analisado no tópico 2, o termo prova fora colocado de forma inadequada, pois não se trata de fato, mas sim de uma matéria de direito que é uma questão de fato por ser uma excepcionalidade ao dogma do iuria novit curia. Esse caráter excepcional já estava consagrada no nível internacional desde da Convenção de Havana de 1928, conhecida como o Código de Bustamante ${ }^{39}$.

$\mathrm{Na}$ dinâmica do Direito Internacional privado, o Direito estrangeiro rapidamente deixou de ser enquadrado como parte do livro de Provas (ou Teoria Geral das Provas), pois nunca foi meio de convencimento do juiz sobre fatos controversos alegados pelas partes da lide. Trata-se de matéria de cooperação judiciária internacional, pelo qual se busca a informação sobre o Direito estrangeiro para aplicar o mesmo de forma correta a lide. Isto é, trata-se de parte da interpretação jurídica em descobrir qual é a premissa maior aplicável ao fato conflituosa em foco.

Esse entendimento foi adotado na realização da Convenção Interamericana sobre prova da informação do Direito Estrangeiro, Montevidéu, Uruguai, em 8 de maio de 1979 e incorporada ao ordenamento jurídico pelo decreto $\mathrm{n}^{\circ} 1.925$, de 10 de junho de 1996, especialmente em seu art. $1^{\circ} .^{40}$

39 “Capitulo II REGRAS ESPECIAES SOBRE A PROVA DE LEIS ESTRANGEIRA. Art. 408. Os juizes e tribunaes de cada Estado contractante applicarão de officio, quando fôr o caso, as leis dos demais, sem prejuizo dos meios probatorios a que este capitulo se refere" (BRASIL. Decreto $\mathbf{n}^{\circ} \mathbf{1 8 . 8 7 1}$, de 13 de agosto de 1929. Promulga a Convenção de direito internacional privado, de Havana. Disponível online em http://www2.camara.leg.br/legin/fed/decret/1920-1929/decreto-18871-13-agosto-1929-549000publicacaooriginal-64246-pe.html acessado em 10 de junho de 2018.

40 "Esta Convenção tem por objeto estabelecer normas sobre a cooperação internacional entre Estados Partes para a obtenção de elementos de prova e informação a respeito do direito de cada um deles." (BRASIL. Decreto $\mathbf{n}^{\circ} 1.925$, de 10 de junho de 1996. Promulga a Convenção Interamericana sobre Prova de Informação acerca do Direito Estrangeiro, concluída em Montevidéu, Uruguai, em 8 de maio de 1979. Disponível online em http://www.planalto.gov.br/ccivil_03/decreto/1996/D1925.htm acessado em 10 de junho de 2018. 
Esse diploma legislativo é esclarecedor ao determinar que não é o Direito estrangeiro objeto de prova, mas sim a sua informação, além de prever procedimento ex officio para sua realização através de procedimento diplomático entre autoridades dos Estados parte $\left(\operatorname{art} .4^{\circ}\right)^{41}$.

Nessa mesma esteira, a Convenção Interamericana sobre normas gerais de Direito Internacional Privado Montevidéu,1979, ratificada pelo Decreto ${ }^{\circ}{ }^{1}$.979/1996 estabeleceu expressamente que a aplicação do direito estrangeiro é uma obrigação do juiz e das autoridades dos Estados Partes e mantendo o direito das partes em fazer prova própria sobre o direito estrangeiro alegado $\left(\operatorname{art} .2^{\circ}\right)^{42}$.

Com o novo CPC, foi a vez do legislador de 2015 ignorar essa situação e repetir o equívoco de enquadrar a informação do Direito estrangeiro como parte do capítulo de Provas.

O segundo problema existente na tradição legislativa sobre a informação do direito estrangeiro está na a utilização da expressão “A parte que alegar” e seu dúbio significado. Somente pode o juiz aplicar direito estrangeiro ao caso, se esse direito for alegado por uma das partes?

A indagação sobre a necessidade de invocação pela parte do Direito estrangeiro foi enfrentada pelo Superior Tribunal de Justiça (STJ), quando do julgamento do REsp. 254544 MG/0033853-2, no qual estabeleceu a posição de que "não carece, pois, de provocação das partes para verificar se o caso há de ser regido por alguma disposição de direito estrangeiro" $"$.

\footnotetext{
41 "As autoridades jurisdicionais dos Estados Partes nesta Convenção poderão solicitar as informações a que se refere a alínea $\mathrm{c}$ do artigo 3. Os Estados Partes poderão estender a aplicação desta Convenção aos pedidos de informações de outras autoridades. Sem prejuízo do acima estipulado, poder-se-á atender às solicitações de outras autoridades que se refiram aos elementos de prova indicados nas alíneas a e b do artigo 3". (BRASIL. Decreto $\mathbf{n}^{\circ} \mathbf{1 . 9 2 5 ,}$ de 10 de junho de 1996. Promulga a Convenção Interamericana sobre Prova de Informação acerca do Direito Estrangeiro, concluída em Montevidéu, Uruguai, em 8 de maio de 1979. Disponível online em http://www.planalto.gov.br/ccivil_03/decreto/1996/D1925.htm acessado em $10 \mathrm{de}$ junho de 2018.

${ }_{42}$ BRASIL. Decreto $\mathbf{n}^{\circ}$ 1.979, de 9 de Agosto de 1996. Promulga a Convenção Interamericana sobre Normas Gerais de Direito Internacional Privado, concluída em Montevidéu, Uruguai, em 8 de maio de 1979. Disponível online em http://www.planalto.gov.br/ccivil_03/decreto/1996/D1979.htm acessado em 10 de junho de 2018.

${ }^{43}$ STJ - REsp: 254544 MG 2000/0033853-2, Relator: Ministro Eduardo Ribeiro, Data de Julgamento: 18/05/2000, T3 - Terceira Turma, data de publicação: DJ 14.08.2000 p.170 LEXSTJ vol.135 p.239 RSTJ vol. 137, p.380).
} 
O STJ baseou sua posição na premissa de que normas de Direito Internacional Privado são normas do Direito interno, logo obrigatórias ${ }^{44}$. Ao estabelecer o entendimento da aplicação ex officio, surgiu um problema acessório a aplicação do Direito estrangeiro: como fica a situação em que o direito estrangeiro é incidente, mas as partes não o alegaram? Ou melhor, não havendo a alegação das partes, pode o juiz demandar das mesmas a produção da informação?

Diante dessa situação, o STJ utilizou uma interpretação literal do art.337 CPC/1973 e estabeleceu o posicionamento de que o juiz não pode criar esse ônus para as partes pela lei processual não prevê-la, somente podendo contar com sua colaboração seguindo o entendimento da doutrina de José Carlos Babosa Moreira sobre o assunto ${ }^{45}$.

A legislação de 2015 também ignorou essa questão e ao fazê-lo criou o terceiro problema: regulamentação insuficiente.

$\mathrm{Na}$ simples leitura do CPC/2015, nota-se que, apesar dos notáveis avanços no que tange a cooperação internacional, a questão da informação do Direito estrangeiro mantevese igual as legislações anteriores. A novel codificação mantém válidas questões quase centenárias, sobre como deve ser o procedimento para realização da prova não alegada? Quais os meios de prova que essa informação deve ser prestada pelas partes? Qual a relação entre a informação produzida e o "livre convencimento" do juiz? E, em caso de lacuna do Direito Estrangeiro incidente, qual o procedimento para sua solução?

Para essas questões ignoradas pelo legislador de 2015, o Ordenamento jurídico brasileiro tem de se socorrer ao Decreto n ${ }^{\circ}$ 1925/1996 e os artigos 409 até 411 do Decreto $\mathrm{n}^{\circ}$ 18.871/1929 e gerar um problema acessório: todos são tratados regionais e seu âmbito

\footnotetext{
44 "Não há dúvida alguma de que, em certas circunstâncias, a Justiça brasileira haverá de aplicar o direito estrangeiro. Isso resulta de normas de Direito Internacional Privado que, apesar do nome, são de direito interno. Caso deixasse de fazê-lo, estaria negando aplicação de tais normas, integrantes do ordenamento nacional" STJ - REsp: 254544 MG 2000/0033853-2, Relator: Ministro Eduardo Ribeiro, Data de Julgamento: 18/05/2000, T3 - Terceira Turma, data de publicação: DJ 14.08.2000 p.170 LEXSTJ vol.135 p.239 RSTJ vol. 137, p.380).

45 "Regra tradicional em nosso direito, com raízes nas Ordenações, a de que à parte que inovar o direito estrangeiro poderá ser determinado que lhe prove teor e vigência. Não se há de ter a norma como sem razão. $\mathrm{O}$ ônus será da parte quando essa o invoque. Ao juiz será dado dispensá-la de fazê-lo, mas não haverá de criar um ônus que a lei não atribui à parte. (...) A respeito do tema pude encontrar, versando-o diretamente, trabalho doutrinário de Barbosa Moreira, sustentando o entendimento exposto".'(STJ - REsp: 254544 MG 2000/0033853-2, Relator: Ministro Eduardo Ribeiro, Data de Julgamento: 18/05/2000, T3 - Terceira Turma, data de publicação: DJ 14.08.2000 p.170 LEXSTJ vol.135 p.239 RSTJ vol. 137, p.380).
} 
de aplicação é limitado aos Estados partes, bem como a própria natureza suis generis da incorporação de tratados no Direito brasileiro.

\section{CONCLUSÕES}

Encerrando o presente estudo, se espera ter evidenciado os problemas que surgem com a concepção do Direito estrangeiro como um fato, erro que implica em compreender o fenômeno de forma viciada, contaminando a própria interpretação da expressão Prova do Direito Estrangeiro, pois trata-se de informação sobre o Direito estrangeiro, a qual admite ser realizada por provas processuais, quando o ônus recai sobre as partes, ou realizada por meio de cooperação judiciária - seja por procedimento próprio (Decreto 1.925), seja por auxilio direto (art. 30, I do CPC/2015) ou outro instrumento de cooperação internacional (art.27, II segunda hipótese do CPC/2015).

Também se conclui que o legislador do Código de Processo Civil de 2015 repetiu os mesmos equívocos das legislações processuais anteriores, tratando o assunto no livro errado (Das Provas) e não estabelecendo uma regulamentação completa sobre o procedimento de realização, mantendo em aberto questões quanto o procedimento de sua realização e da insuficiência do Direito estrangeiro para a lide em foco, omissões que contribuem para a complexidade da aplicação do Direito estrangeiro no Judiciário brasileiro por ausência de regras especificas.

Em suma, espera-se ter-se atingido a finalidade de demonstrar que o instituto da Prova do Direito Estrangeiro está eivada de compreensões equivocadas por parte da doutrina brasileira e que acarretaram a repetição de equívocos históricos em sua regulamentação, gerando uma estagnação na evolução da matéria sob o ponto de vista processual.

\section{REFERÊNCIAS}


ALMEIDA, Candido M. de. Código philippino ou ordenações e leis do reino de

Portugal recompiladas por mandado d'el-rey D. Philippe I. 14 ed. Rio de Janeiro:

Typhographia do Instituto Philomathico, 1870, t.3,

ANDRADE FIGUEIRA, 14 $14^{\text {a }}$ Reunião em 21 de outubro de 1901. In: BRASIL. Código

Civil brasileiro: trabalhos relativos à sua elaboração. Rio de Janeiro: Imprensa

Nacional, volume 3, p.291 - Disponível para descarregar em http://bd.camara.gov.br/bd/handle/bdcamara/14356 )

BAPTISTA, Luiz Olavo. Aplicação do direito estrangeiro pelo juiz brasileiro. In: BAPTISTA, Olavo \& MAZZUOLI, Valério de O (orgs.) Doutrinas essenciais de direito internacional: direito internacional privado: teoria e prática. São Paulo: Editora Revista dos Tribunais, 2012,

BAUMBACH, Adolf; LAUTERBACH, Wolfgang; HARTMANN, Peter. Zivilprozessordnung. 62 ed. München: Verlag C. H. Beck, 2004, p.1153-1154.

BEVILAQUA, Clovis. Princípios elementares de direito internacional privado. Campinas: RED Livros, 2002, p.69

BUSCH, Benjamin. When Law is Fact. Fordham Law Review. Vol. 24. Issue 646, 1955, p.647 disponível online em http://ir.lawnet.fordham.edu/flr/vol24/iss4/8

BRASIL. Decreto $\mathbf{n}^{\circ}$ 1.925, de 10 de junho de 1996. Promulga a Convenção Interamericana sobre Prova de Informação acerca do Direito Estrangeiro, concluída em Montevidéu, Uruguai, em 8 de maio de 1979. Disponível online em http://www.planalto.gov.br/ccivil_03/decreto/1996/D1925.htm

Decreto $\mathrm{n}^{\circ}$ 1.979, de 9 de Agosto de 1996. Promulga a Convenção Interamericana sobre Normas Gerais de Direito Internacional Privado, concluída em Montevidéu, Uruguai, em 8 de maio de 1979. Disponível online em http://www.planalto.gov.br/ccivil_03/decreto/1996/D1979.htm

Decreto $\mathrm{n}^{\circ} \mathbf{1 8 . 8 7 1}$, de 13 de agosto de 1929. Promulga a Convenção de direito internacional privado, de Havana. Disponível online em http://www2.camara.leg.br/legin/fed/decret/1920-1929/decreto-18871-13-agosto1929-549000-publicacaooriginal-64246-pe.html

Decreto $n^{\circ}$ 596, de 19 de julho de 1890. Reorganiza as Juntas e Inspectorias Commerciaes e dá-lhes novo regulamento. Disponível online em 
Rio de Janeiro. Ano 13. Volume 20. Número 3. Setembro a Dezembro de 2019

Periódico Quadrimestral da Pós-Graduação Stricto Sensu em Direito Processual da UERJ

Patrono: José Carlos Barbosa Moreira (in mem.). ISSN 1982-7636. pp. 386-408 www.redp.uerj.br

http://www2.camara.leg.br/legin/fed/decret/1824-1899/decreto-596-19-julho-1890-

505086-publicacaooriginal-1-pe.html

Lei 3.071, de $1^{\circ}$ de janeiro de 1916. Código Civil dos Estados Unidos do

Brasil. Disponível online em http://www.planalto.gov.br/ccivil_03/Leis/L3071.htm acessado em 9 de junho de 2018.

CARNELUTTI, Francesco. A prova civil. Tradução: Lisa Pary Scarpa. Campinas: Bookseller, 2002

CASTRO, Amilcar de. Direito Internacional privado. Atualização: Osiris Rocha. 5 ed. Rio de Janeiro: Forense, 2004,

CHIOVENDA, Giuseppe. Instituições de direito processual civil. Tradutor: Paolo Capitanio. $3^{\mathrm{a}}$ ed. Campinas: Bookseller, vol. III, 2002, p.113.

DISTRITO FEDERAL. Decreto $n^{\circ}$ 16.752, de 31 de Dezembro de 1924. Põe em execução o Código do processo civil e commercial no Distrito Federal. Disponível online em http://www2.camara.leg.br/legin/fed/decret/1920-1929/decreto-16752-31dezembro-1924-516249-publicacaooriginal-139889-pe.html

DEUTSCHER REICHSANZEIGEN: Amtliches Mitteilungsblatt des Deutschen Reiches. Civilprozeßordnung Buch 2, disponível online em https://deutscherreichsanzeiger.de/Gesetze/blog/1877/02/19/cpo-buch-2/

FREITAS, Augusto Teixeira de. Código Civil: esboço por A. Teixeira de Freitas. Rio de Janeiro: Ministério da justiça e negócios interiores, 1952

MACEDO, Elaine H. Jurisdição e processo. Crítica histórica e perspectivas para o terceiro milênio. Porto Alegre: Livraria do Advogado, 2005

PONTES DE MIRANDA, Francisco C. Tratado de Direito internacional privado. Tomo I - Fundamentos e parte geral. Rio de Janeiro: José Olympio Editora, 1935

RAATZ, Igor \& SANTANNA, Gustavo da S. História do processo civil brasileiro: do código de 1939 ao código de 1973. In: Justiça e História. Porto Alegre: Tribunal de Justiça do Estado do Rio Grande do Sul, 2012, vol.9 n 17 e 18, p. 12 disponível online

em http://www.tjrs.jus.br/site/poder_judiciario/historia/memorial_do_poder_judiciario/m emorial_judiciario_gaucho/revista_justica_e _historia/index.html 
RIBAS, Antonio J. Consolidação das leis do processo civil. Com colloboração de seu filho Dr. Julio A. Ribas. Rio de Janeiro: Dias da Silva Junior Typographo-editor, 1879, v.01, p.248 disponível online para descarregar em http://www2.senado.leg.br/bdsf/item/id/220533

SÃO PAULO. Lei $\mathbf{n}^{\circ}$ 2.421, de 14 de Janeiro de 1930. Código de Processo civil e $\begin{array}{llll}\text { commercial. } & \text { Disponível online }\end{array}$ https://www.al.sp.gov.br/repositorio/legislacao/lei/1930/lei-2421-14.01.1930.html

STJ - REsp: 254544 MG 2000/0033853-2, Relator: Ministro Eduardo Ribeiro, Data de Julgamento: 18/05/2000, T3 - Terceira Turma, data de publicação: DJ 14.08.2000 p.170 LEXSTJ vol.135 p.239 RSTJ vol. 137

STORY, Joseph. Commentaries on the conflict of laws, foreign and domestic, in regard to contracts, rights, and Remedies, and especially in regard to marriages, divorces, wills, successions, and judgements. 2nd ed. Union, New Jersey: The Lawbook Exchange ltda. 2005

UNITED STATES OF AMERICA. Federal Rules of Civil Procedure: rule 44.1 Determining Foreign Law. In: Legal Information Institute. Disponível online em https://www.law.cornell.edu/rules/frcp/rule 38

VALLADÃO, HAROLDO. Direito internacional privado: em base histórica $e$ comparativa, positiva e doutrinaria, especialmente dos Estados americanos. Introdução e Parte Geral. Rio de Janeiro: Livraria Freitas Bastos S.A., 1968

Von BAR, Christian; MANKOWSKI, Peter. Internationales Privatrecht.Band I Allgemeine Lehren. München: Verlag C.H. Beck, 2003, vol. 1

WESTLAKE, John. A treatise on private international law with principal reference to its practice in England. London: William Maxwell \& Son, 1880,

WILSON, Mathew J. Demystifying the determination of foreign law in U.S. courts: opening the door to a greater global understanding. Akron Law Publications. $\begin{array}{llll}\text { Paper } & 227 & \text { disponível on }\end{array}$ http://ideaexchange.uakron.edu/ua_law_publications/227 